\title{
RET receptor expression and interaction with TRK receptors in neuroblastomas
}

\author{
LAURA H. TETRI ${ }^{1}$, VENKATADRI KOLLA ${ }^{1}$, REBECCA L. GOLDEN ${ }^{1}$, RADHIKA IYER ${ }^{1}$, \\ JAMIE L. CROUCHER ${ }^{1}$, JEE-HYE CHOI ${ }^{1}$, SUZANNE P. MACFARLAND ${ }^{1}$, \\ KOUMUDI NARAPARAJU ${ }^{1}$, PENG GUAN ${ }^{1}$, FERRO NGUYEN ${ }^{1}$, \\ KRUTIKA S. GAONKAR ${ }^{2,3}$, PICHAI RAMAN ${ }^{2,3}$ and GARRETT M. BRODEUR ${ }^{1}$ \\ ${ }^{1}$ Division of Oncology, Department of Pediatrics, The Children's Hospital of Philadelphia \\ and The University of Pennsylvania; ${ }^{2}$ Department of Biomedical and Health Informatics, \\ ${ }^{3}$ Center for Data-Driven Discovery in Biomedicine, Children's Hospital of Philadelphia, \\ Philadelphia, PA 19104-4302, USA
}

Received January 22, 2019; Accepted August 1, 2019

DOI: $10.3892 / o r .2020 .7583$

\begin{abstract}
Neuroblastomas (NBs) have heterogeneous clinical behavior, from spontaneous regression or differentiation to relentless progression. Evidence from our laboratory and others suggests that neurotrophin receptors contribute to these disparate behaviors. Previously, the role of TRK receptors in NB pathogenesis was investigated. In the present study, the expression of RET and its co-receptors in a panel of NB cell lines was investigated and responses to cognate ligands GDNF, NRTN, and ARTN with GFR $\alpha 1-3$ co-receptor expression, respectively were found to be correlated. RET expression was high in NBLS, moderate in SY5Y, low/absent in NBEBc1 and NLF cells. All cell lines expressed at least one of GFR $\alpha$ co-receptors. In addition, NBLS, SY5Y, NBEBc1 and NLF cells showed different morphological changes in response to ligands. As expected, activation of RET/GFR $\alpha 3$ by ARTN resulted in RET phosphorylation. Interestingly, activation of TrkA by its cognate ligand NGF resulted in RET phosphorylation at Y905, Y1015, and Y1062, and this was
\end{abstract}

Correspondence to: Dr Garrett M. Brodeur, Department of Pediatrics, The Children's Hospital of Philadelphia and The University of Pennsylvania, 3501 Civic Center Blvd., Philadelphia, PA 19104-4302, USA

E-mail: brodeur@email.chop.edu

Abbreviations: RT-PCR, reverse transcriptase polymerase chain reaction; GDNF, glial cell line-derived neurotrophic factor; NRTN, neurturin; ARTN, artemin; PSPN, persephin; NGF, nerve growth factor; BDNF, brain-derived neurotrophic factor; RTK, receptor tyrosine kinase

Key words: neuroblastoma, RET, glial cell line-derived neurotrophic factor, neurturin, artemin, neurotrophic receptor tyrosine kinase 1, neurotrophic receptor tyrosine kinase 2, nerve growth factor, brain-derived neurotrophic factor inhibited in a dose-dependent manner by the TRK inhibitor (CEP-701). Conversely, RET activation by ARTN in NBLS cells led to phosphorylation of TrkA. This suggests a physical association between RET and TRK proteins, and cross-talk between these two receptor pathways. Finally, RET, GFR and TRK expression in primary tumors was investigated and a significant association between RET, its co-receptors and TRK expression was demonstrated. Thus, the present data support a complex model of interacting neurotrophin receptor pathways in the regulation of cell growth and differentiation in NBs.

\section{Introduction}

Neuroblastoma (NB) is the most common extracranial solid tumor of childhood, accounting for $8 \%$ of childhood cancers and $15 \%$ of childhood cancer deaths. It arises from sympathoadrenal precursors and generally occurs in the adrenal medulla or along the sympathetic chain. NBs demonstrate clinical heterogeneity, from spontaneous regression to relentless progression $(1,2)$. We and others have identified different patterns of genetic change that underlie these disparate clinical behaviors $(3,4)$, and that receptor tyrosine kinase (RTK) expression likely contributes to this $(5,6)$. Several RTKs have been implicated in the pathogenesis or clinical behavior of NBs including TRK genes, ALK and RET. The TRK family of neurotrophin receptors plays critical roles in the development and maintenance of the central and peripheral nervous system (5). Neurotrophic receptor tyrosine kinase 1 (NTRK1, also known as TrkA), neurotrophic receptor tyrosine kinase 2 (NTRK2, also known as TrkB) and neurotrophic receptor tyrosine kinase 3 (NTRK3, also known as TrkC) are the cognate receptors for nerve growth factor (NGF), brain-derived neurotrophic factor (BDNF) and neurotrophin-3 (NT3), respectively. TrkB also binds to NT4, and all three can be activated by NT3. TrkA (and TrkC) are important for the development of sensory and sympathetic neurons, whereas TrkB is important for motoneuron development (7). 
RET is an RTK that is expressed in many NB tumors and tumor-derived cell lines (8-10). RET is essential for the migration, growth, axon formation, and differentiation of normal sympathetic neurons during development (11-13). RET is one of few RTKs that requires a co-receptor for ligand binding, rather than direct ligand binding (14). Most studies of RET in NB have not investigated co-receptor expression, or the correlation between co-receptor expression and ligand-specific activation. The four RET ligands are glial-cell line derived neurotrophic factor (GDNF), neurturin (NRTN), artemin (ARTN), and persephin (PSPN). They associate with GDNF co-receptors GFR $\alpha 1-G F R \alpha 4$, respectively. A ligand homodimer must bind to a co-receptor (GFR $\alpha 1-G F R \alpha 4)$ to induce co-receptor homodimerization (15). The ligand/co-receptor complex then recruits RET into lipid rafts, leading to homodimerization and autophosphorylation of the RET tyrosine kinase domain $(11,16-18)$.

RET phosphorylation leads to the activation of specific post-receptor signaling pathways. Of the 16 RET autophosphorylation sites, the three most important for signaling are Y905, Y1015 and Y1062 (11,17,18). RET is further regulated by posttranslational modifications and exists in the cell in three forms: Unglycosylated $(\sim 120 \mathrm{kDa})$, partially glycosylated $(\sim 150 \mathrm{kDa})$-present only at the endoplasmic reticulum, and fully glycosylated ( 170 kDa)-present on the cell surface (11). Besides differences in glycosylation, RET also exists as two main transcriptional isoforms-RET9 and RET51-which have different signaling properties $(19,20)$.

RET is expressed in most NB tumors and cell lines, although it has not been associated with patient outcome (8-10,19,21-23). Thus far, no mutations or genomic alterations have been identified leading to activation (or inactivation) of RET in NB (22-25). Higher RET mRNA and protein expression levels have been associated with differentiation of NB cells (9,26-33), but other studies have suggested that RET may play a role in proliferation or metastasis in NBs $(31,34-36)$. The pattern of TRK family gene expression clearly contributes to the survival, growth, and differentiation of NBs, and it has been suggested that RET can cooperate with TrkA and B to cause neuronal differentiation in response to ligands or to 13-cis retinoic acid $(37,38)$. However, the direct or indirect interaction of RET with other receptors has not been fully explored.

Here, the expression of the RET and its co-receptors was investigated, as well as TRKs in a panel of NB cell lines and the correlation of their responses to GDNF, NRTN, and ARTN with GFR $\alpha 1-3$ expression, respectively, was investigated. It was also demonstrated TRK activation by ARTN, and RET activation by NGF, suggesting a physical association between RET and TrkA receptors. Finally, the expression of RET, GFRs and TRKs in publicly available databases of NB mRNA expression was examined, and significant associations were validated in additional databases. The present data provide insights into the complex interactions of these two receptor pathways in neuroblastoma that may contribute to NB pathogenesis or differentiation.

\section{Materials and methods}

Cell lines, culture conditions. All cell lines used in this study were maintained in our lab or obtained from American
Type Culture Collection. The NLF line was first isolated at Washington University (St. Louis, MO, USA) in the 1970's by Dr Milton Goldstein. Both TrkA and TrkB clones were developed in Dr Brodeur's laboratory. Cell lines were grown in RPMI-1640 medium containing $10 \%$ fetal bovine serum, $500 \mathrm{U} / 1$ penicillin and $500 \mu \mathrm{g} / 1$ streptomycin, $2 \mathrm{mML}$-glutamine and $25 \mathrm{mg} / \mathrm{l}$ gentamicin (all from Gibco; Thermo Fisher Scientific, Inc.). Cells were grown at $37^{\circ} \mathrm{C}$ in a humidified incubator with $95 \%$ air and $5 \% \mathrm{CO}_{2}$. TRK-null SH-SY5Y cells were stably transfected with TrkA (SY5Y-TrkA, clone P23A) or TrkB (SY5Y-TrkB, clone BR6) (39-52). Transfected cells were maintained in media containing $0.3 \mathrm{mg} / \mathrm{ml} \mathrm{G} 418$ sulfate (Corning Inc.). Other NB lines used in this study were NBLS, NBEBc1 and NLF. Cells were harvested using 0.2\% tetrasodium EDTA in phosphate buffered saline. We tested these cell lines for endotoxins, mycoplasma, bacterial and viral contamination, as well as genetic identity validation by multiplex PCR techniques. These tests are performed annually at our facility.

Prior to treatment with ligand or drug, cells were serum-starved in RPMI-1640 with $1 \%$ fetal bovine serum (Life Technologies; Thermo Fisher Scientific, Inc.) to minimize serum factor signaling. Cells were treated with lestaurtinib (CEP-701, Cephalon/TEVA Pharmaceutical Industries), a TRK-selective inhibitor, at the indicated concentration for one hour before ligand treatment. Cells were treated with $50 \mathrm{ng} / \mathrm{ml}$ of GDNF, NRTN, and ARTN (R\&D Systems, Inc.), or $100 \mathrm{ng} / \mathrm{ml} \mathrm{NGF}$ and BDNF (PeproTech, Inc.) in RPMI-1640 with $1 \%$ fetal bovine serum for $15 \mathrm{~min}$ before cell lysis. Control cells received either the same volume of PBS or no treatment. For longer treatments to determine effects on morphology, cells remained in the drug and ligand-containing media for 24 h, 3 days or 6 days.

Antibodies and other reagents. Antibodies targeting phosphorylated (p) RET-Y905 (cat. no. 3221), TRK-Y490 (cat. no. 9141) and RET (cat. no. 14556) were obtained from Cell Signaling Technology, Inc. Antibodies targeting pRET-Y1015 (cat. no. ab74154) and pRET-Y1062 (cat. no. ab51103) were purchased from Abcam. GFR $\alpha 1-3$ (cat. nos. MAB7141, MAB6131 and MAB6701, respectively) antibodies were from R\&D systems, Inc. RET (isoforms 51, cat. no. sc-1290) and pan-TRK (cat. no. sc-11) antibodies were obtained from Santa Cruz Biotechnology, Inc. NGF and BDNF (50 ng/ml final working concentrations) were obtained from PeproTech, Inc.

Whole cell extracts. To prepare whole cell extracts, cells were lysed and protein collected using cell lysis buffer (Cell Signaling) with $500 \mathrm{ml}$ of buffer concentrate, $50 \mu \mathrm{l}$ of $100 \mathrm{mM}$ PMSF in ethanol, $750 \mu \mathrm{l}$ of Protease inhibitor from cOmplete $^{\mathrm{TM}}$, Mini Protease Inhibitor Cocktail Tablets (Roche Diagnostics) and $3.75 \mathrm{ml}$ of distilled water.

RET inhibition studies. NBLS cells were induced with RET ligand ARTN (50 ng/ml) and inhibited using increasing concentrations of CEP-701 (10, 50, 100, 200 and $400 \mathrm{nM})$. Whole cell extracts were prepared as aforementioned, and used for western blot analysis.

Western blot analysis. Whole cell extracts $(100 \mu \mathrm{g})$ were subjected to polyacrylamide gel electrophoresis 
(4-12\% SDS-PAGE), using NuPAGE Bis-Tris gels with MOPS-SDS Running Buffer (Invitrogen; Thermo Fisher Scientific, Inc.). Proteins were transferred to nitrocellulose membranes (GE Healthcare Life Sciences). Membranes were blocked with 5\% non-fat milk in PBS-Tween-20, and incubated with primary antibodies $(1: 1,000)$ overnight at $4^{\circ} \mathrm{C}$, either in $5 \%$ non-fat milk or $1 \%$ BSA (for phosphorylated-specific antibodies). After 3-4 washes with PBS-Tween-20, the membranes were incubated with secondary antibodies $(1: 3,000)$ in similar buffers at room temperature for $1 \mathrm{~h}$. Blots were washed four time with PBS-Tween-20, developed using chemiluminescence reagent (Invitrogen; Thermo Fisher Scientific, Inc.) and signals were detected using autoradiography.

$R N A$ isolation and reverse-transcription-quantitative $P C R$ $(R T-q P C R)$. Total RNA was isolated from cell pellets using the RNeasy Mini kit (Qiagen, Inc.) and quantified using Nanodrop spectrometer (Thermo Fisher Scientific, Inc.). cDNA was prepared from total RNA using the High Capacity cDNA Reverse Transcription kit (Applied Biosystems; Thermo Fisher Scientific, Inc.). qPCR was performed using an ABI 7900HT Fast Real-Time PCR system with TaqMan Gene Expression Assays (Applied Biosystems; Thermo Fisher Scientific, Inc.) for RET (RET: Hs01120032_m1), GFR $\alpha 1-3$ (GFR $\alpha 1: H s 00237133 \_m 1 ; G F R \alpha 2: H s 00394700 \_m 1$; GFRa3: Hs00181751) and GAPDH (GAPDH: Hs99999905_ $\mathrm{m} 1)$. All samples were run in triplicate, and each experiment was conducted at least three times. Values were calculated as relative rates from a standard curve, and GAPDH was used as an internal control.

Phase contrast microscopy. Cell morphology was assessed using phase-contrast microscopy, and captured images at 20x magnification (Leica Microsystems Inc.). For longer treatments to examine the effects of ligand on cell morphology, the media was changed every 3 days, and fresh ligand was added. Various NB cell lines were plated in either 6 -well or $10 \mathrm{~cm}$ culture dishes, and cells were treated with GDNF, ARTN or NRTN. Ligand-induced cells were assessed for neuronal differentiation by changes in cell shape, and by measuring neurite outgrowth. Cells were considered differentiated when they had three or more times the size of undifferentiated cells, with development of euchromatin and prominent nucleoli. Neurite outgrowth was also assessed by counting the number of cells that had neurites extending more than the length in longest diameter of the cell, as assessed by ocular micrometer measurement.

Statistical analysis. For analysis of gene expression, statistical analyses were performed using GraphPad Prism and the Prism-ANOVA method. Each experiment was performed at least three times, and triplicate readings were used and reported for all P-values. Data are expressed as the standard error of the mean. Values are the mean of triplicate readings from three or more independent experiments and $\mathrm{P}<0.05$ was considered to indicate a statistically significant difference.

Relative expression of RET and its co-receptors was assessed by western blotting and was scored qualitatively from '+++' for the highly RET positive NBLS line to '-' for the NLF line. A similar approach was used for GDNF $\alpha 1-3$ expression
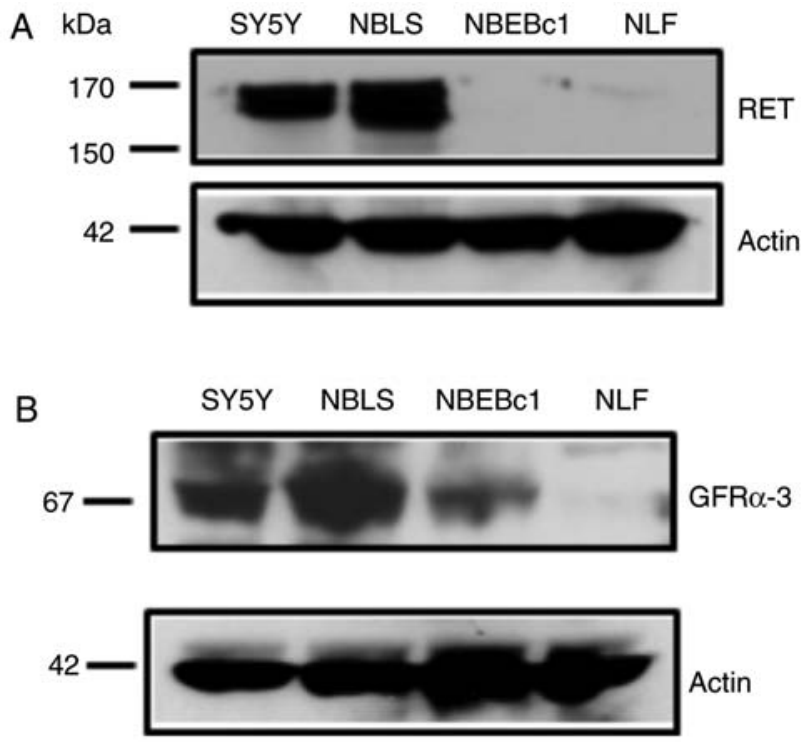

Figure 1. RET expression in NB cell lines. (A) Whole cell extracts from SY5Y, NBLS, NBEBc1 and NLF cell lines were subjected to western blotting. SY5Y and NBLS cells show the highest levels of RET expression. (B) Expression of co-receptor GFR $\alpha 3$ is high in NBLS, moderate in SY5Y, low in NBEBcl and absent in NLF cells.

and for RET phosphorylation. Morphologic changes, such as cell body enlargement, flattening and neurite outgrowth, were also quantitated on a '-' to ' +++ ' scale, where '-' indicated no change, '十' indicated a modest change, '++' indicated a moderate change, and ' +++ ' indicated a dramatic change, based on direct inspection of phase-contrast images.

Data from publicly available NB microarray expression and RNA-seq studies were analyzed for the expression of RET with its co-receptors GFR $\alpha 1,-2,-3$, and -4, as well as with NTRK1 and -2, to determine if there were significant associations. The ggplot2 package (version 2.21; https://mran.microsoft.com/snapshot/2017-04-11/web/packages/ggplot2/index.html) was used to generate scatter plots comparing RET with GFR $\alpha 1,2,3,4$ and NTRK1, 2 from the TARGET NB RNA-sequencing data (53). Pearson's correlation analysis was used to estimate correlation between RET and the expression of the GFR $\alpha 1$ receptors. Meta-analysis was performed using the meta package (54). Both fixed and random effects model for the analysis and forest plots were generated to summarize the data. All data was analyzed using the R statistical (version 3.43) language and framework.

\section{Results}

Expression of RET and its co-receptors in NB cell lines. In order to determine RET expression levels in a panel of NB cell lines (SY5Y, NBLS NBEBc1 and NLF), western blot analysis using whole cell extracts was performed. RET was detected at moderate to high levels in both the NBLS and SY5Y lines, but it was low/absent in NBEBc1 and NLF cells (Fig. 1A). Next, the expression of endogenous RET co-receptor expression was assessed. GFR $\alpha 3$ was expressed at various levels, ranging from low to high in this panel of NB cell lines, and high expression of GFR $\alpha 3$ was seen in NBLS, with lower levels detected in NBEBc1 (Fig. 1B). In addition, we analyzed mRNA 
Table I. RET and RET co-receptor expression in NB cell lines.

\begin{tabular}{|c|c|c|c|c|c|}
\hline Ligand treatment & Characteristics & NBLS & SY5Y & NB-EBc1 & NLF \\
\hline No treatment & RET expression $^{\mathrm{a}}$ & +++ & ++ & $+/-$ & - \\
\hline No treatment & GFR $\alpha 1$ expression & ++ & - & + & + \\
\hline No treatment & GFR $\alpha 2$ expression & + & - & + & ++ \\
\hline No treatment & GFR $\alpha 3$ expression & +++ & +++ & + & + \\
\hline \multirow[t]{2}{*}{ GDNF treatment } & RET phosphorylation & ++ & + & + & - \\
\hline & Morphologic changes ${ }^{b}$ & + & ++ & + & - \\
\hline \multirow[t]{2}{*}{ NRTN treatment } & RET phosphorylation & ++ & - & + & - \\
\hline & Morphologic changes & ++ & + & + & - \\
\hline \multirow[t]{2}{*}{ ARTN treatment } & RET phosphorylation & +++ & - & + & - \\
\hline & Morphologic changes & ++ & + & + & - \\
\hline
\end{tabular}

'Relative expression of RET and its co-receptors was assessed by western blotting and was scored qualitatively from '+++' for the highly RET positive NBLS line to '-' for the NLF line. A similar approach was used for GDNF 1 1-3 expression and for RET phosphorylation. ${ }^{\mathbf{b}}$ Morphologic changes, such as cell body enlargement, flattening and neurite outgrowth, were also quantitated on a '-' to '+++' scale.
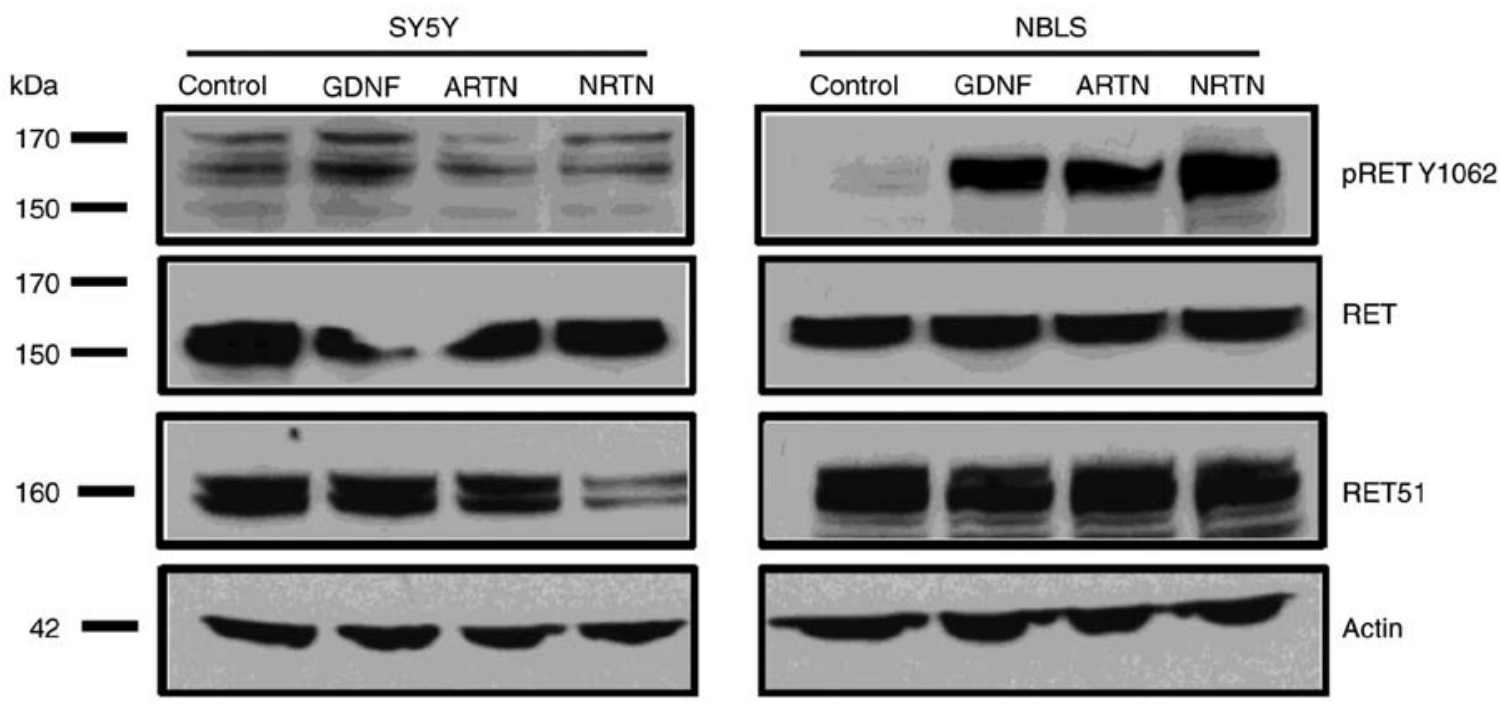

Figure 2. RET phosphorylation in response to ligand. Cell extracts from SY5Y and NBLS were analyzed by western blotting. Phospho-RET is induced by exposure to all three ligands, GDNF, NRTN and ARTN, in NBLS. SY5Y shows modest induction of phosphor-RET by GDNF. NB, neuroblastoma; GDNF, glial cell line-derived neurotrophic factor; ARTN, artemin; NRTN, neurturin.

expression of RET and its co-receptors GFR $\alpha 1-3$ in these cell lines by quantitative RT-PCR. The results correlating RET and co-receptor expression are summarized in Table I. GFR $\alpha 4$ and PSPN expression levels were negative in all cell lines and were excluded from further analysis.

Expression of phospho-RET in NB cell lines. To further investigate whether ligand exposure leads to RET phosphorylation, SY5Y and NBLS cells, which expressed both RET and GFR $\alpha 3$ (Fig. 1), were treated with $50 \mathrm{ng} / \mathrm{ml}$ of ligands GDNF, NRTN and ARTN for $15 \mathrm{~min}$. Whole cell extracts were prepared and western blotting was performed. RET expression in response to ligands was analyzed using a RET-Y1062 antibody. All ligands readily induced phosphorylation of RET in NBLS cells, but there was only a modest increase in phosphorylation of RET in respond to GDNF in SY5Y (Fig. 2). Phosphorylated RET in response to various ligands in different cell lines is shown in Table I. These results confirm that RET activation occurs in NB cell lines by phosphorylation in response to ligand in the presence of their cognate co-receptors.

Morphological changes of $N B$ cell lines in response to RET ligands. Morphological differences in NB cell lines in response to ligands were assessed. SY5Y, NLF, NBLS, and NB-EBc1 cells were exposed to GDNF, ARTN, or NRTN (50 ng/ml) or no ligand, and the cells were assessed qualitatively by phase contrast microscopy at $0,24 \mathrm{~h}, 3$ days, and 6 days. SY5Y cells showed morphologic differentiation and neurite outgrowth in response to GDNF and NRTN, but not ARTN after 6 days of exposure (Fig. 3). NLF cells showed a flattened shape and neurite outgrowth compared to control cells in response to ligand (Fig. 3). NBLS and SY5Y had the highest levels of endogenous RET expression, and showed morphologic 

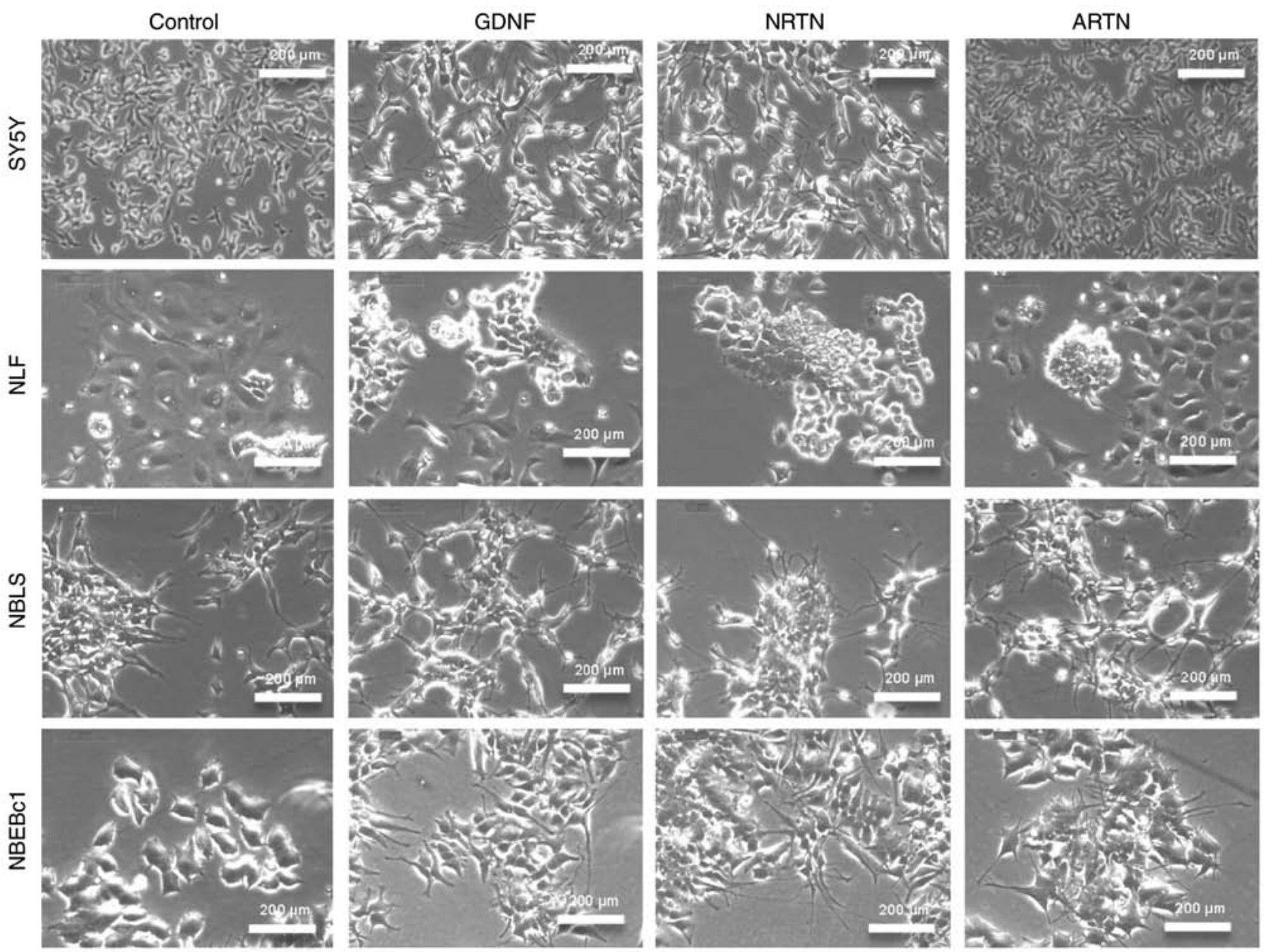

Figure 3. Representative phase contrast images depicting morphology change in response to GDNF, NTRN and ARTN ligands (6 days) in SY5Y, NLF, NBLS and NBEBc1 NB cell lines. Cells respond to ligand activation and show morphological changes, such as cell flattening, cell enlargement and neurite outgrowth, which is most pronounced in NBLS and SY5Y, modest in NBEBc1 and not observed in NLF. NB, neuroblastoma; GDNF, glial cell line-derived neurotrophic factor; ARTN, artemin; NRTN, neurturin.

changes characteristic of differentiation (Fig. 3 and Table I). Neurite outgrowth was observed in NBLS treated with GDNF, NRTN and ARTN, and by 6 days the most dramatic morphologic changes were seen in NRTN- and ARTN-treated cells. NB-EBc1 cells treated with NRTN and ARTN had short neurites at 3 days, and longer, more complex neurites in 6 days. The morphology of the NBLS and NB-EBc1 without ligand exposure did not change at 6 days. These results suggest that there was clear morphological differentiation upon ligand induction in cell lines expressing RET and the corresponding co-receptor.

Effect of CEP-701 on RET expression. Since differential expression of RET and TRK in SY5Y and NBLS cells was observed, the effect of TRK inhibition with CEP-701 was examined. SY5Y is RET positive and TRK null; and NBLS expresses both RET and TRK. These cells were treated with $100 \mathrm{nM}$ CEP-701 for $1 \mathrm{~h}$ before adding ARTN $(50 \mathrm{ng} / \mathrm{ml})$. To examine possible TRK or RET inhibition by CEP-701, western blot analysis with phospho-specific antibodies was performed. Results indicated that CEP-701 significantly inhibited both TRK and RET activation, and there was reduced RET phosphorylation at all three residues (Y905, Y1062 and Y490) in
NBLS and SY5Y cells (Fig. 4A). Interestingly, ARTN treatment activated TRK at tyrosine 490 in NBLS cells, and this was completely inhibited by CEP-701 (Fig. 4A). However, there was no effect of RET ligands on NLF, which is had no RET expression (Fig. 1).

In order to determine the most effective dose of CEP-701 against both RET and TRK, we treated NBLS cells with CEP-701 at 0, 10, 50, 100, 200 and $400 \mathrm{nM}$ concentrations, and performed western blot analysis. Reduced phosphorylation at all three tyrosine residues was observed in a dose dependent manner. CEP-701 inhibited TRK at lower concentrations compared with those required for RET inhibition. RET phosphorylation was almost completely inhibited at $200 \mathrm{nM}$, whereas TRK was completely inhibited at $50 \mathrm{nM}$ (Fig. 4B). These results suggest that RET expression is inhibited by CEP-701, presumably through inhibition of TRK activation, and TRK activation by ARTN requires RET activation.

RET and TRK receptor interactions. Since we observed TrkA phosphorylation upon exposure of NBLS cells to ARTN, which was inhibited by CEP-701 (Fig. 4A), if RET could be activated by exposure of TRK-expressing cells to their cognate ligands 

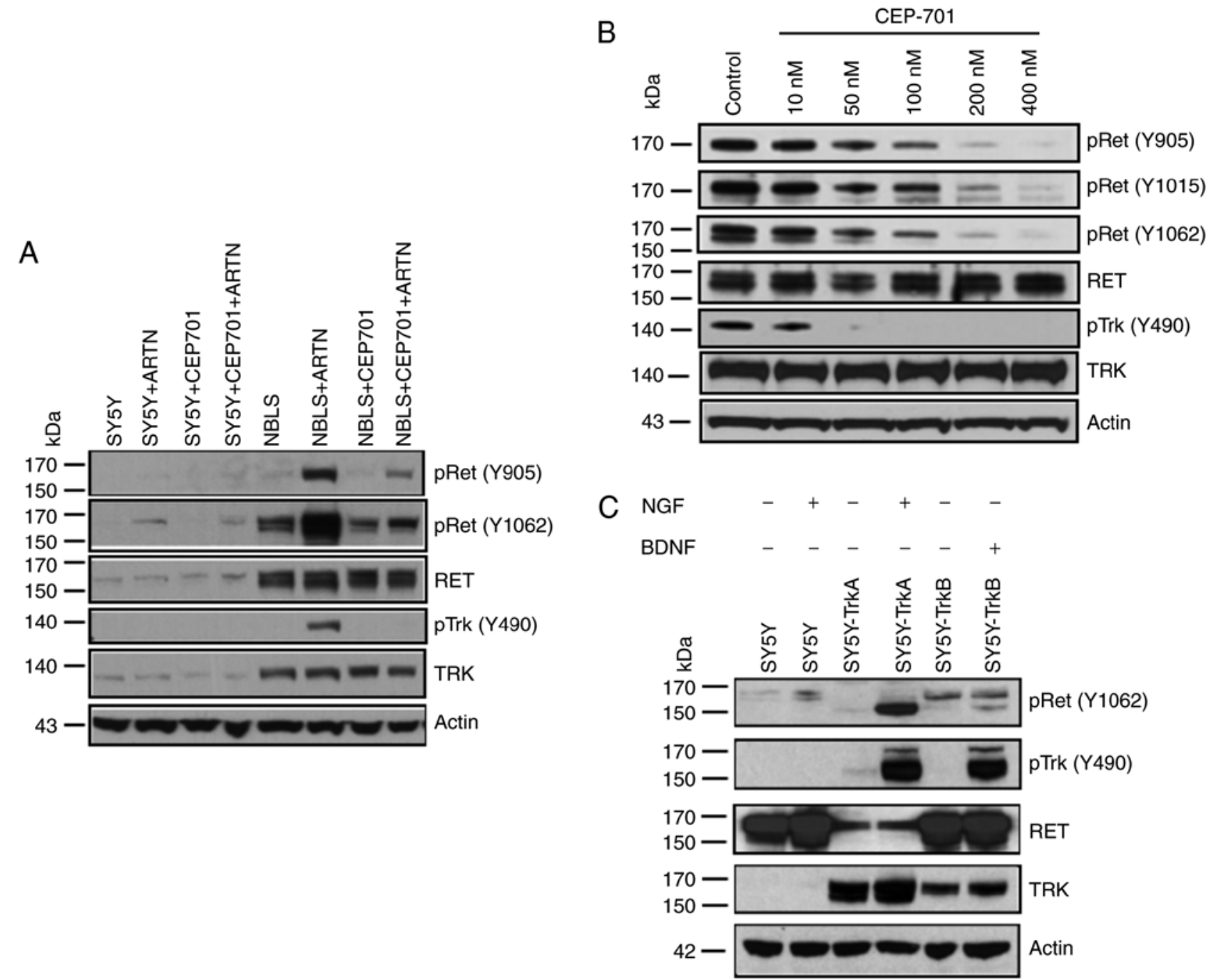

Figure 4. Effect of RET/TRK inhibition by lestaurtinib (CEP701). (A) Inhibition of RET expression by CEP701. SY5Y and NBLS cells were treated with $100 \mathrm{nM}$ CEP701 and/or ARTN, and analyzed for the expression of RET, phospho-RET, TRK, and phospho-TRK. SY5Y cells showed modest induction of phospho-RET by ARTN compared with untreated cells, but the effect of CEP701 could not be assessed due to the lack of TRK expression. NBLS cells showed strong RET activation and TRK activation, and this activation was inhibited by CEP701. (B) Dose dependent inhibition of RET expression by CEP701. NBLS cells were induced with the RET ligand ARTN and inhibited using increasing concentrations of CEP701. Dose dependent inhibition of RET (and TrkA) was observed upon CEP701 exposure. (C) RET phosphorylation in response to TRK ligands. SY5Y (TRK-null), SY5Y-TrkA and SY5Y-TrkB cells were exposed to their cognate ligands (NGF for TrkA, BDNF for TrkB), and phospho-RET, total RET, phospho-TRK, and total TRK expression was measured. RET is phosphorylated strongly by NGF exposure to SY5Y-TrkA, and modestly by BDNF exposure to SY5Y-TrkB.

was investigated next. There was no effect on RET by adding NGF to TRK-null SY5Y cells (Fig. 4C). However, even though RET expression was lower in SY5Y-TrkA cells compared with NBLS cells, it was strongly phosphorylated by adding NGF, and phosphorylated less by adding BDNF to SY5Y-TrkB cells. RET phosphorylation occurs in response to TrkA activation by NGF, and TrkA is phosphorylated in response to RET activation by ARTN, which suggests that RET and TrkA (and possibly TrkB) physically interact and can induce reciprocal activation in response to ligand activation, but this needs to be investigated further.

Association of RET expression with its co-receptors and with TRK genes. Next, mRNA expression of RET with its co-receptors and with $T R K$ genes $(N T R K 1, N T R K 2)$ in a large series of primary NBs was assessed. Data from 249 primary NBs from the NB TARGET Initiative (ocg.cancer. gov/programs/target/projects/neuroblastoma) was analyzed (Fig. 5). There was no correlation between RET expression and GFR $\alpha 1$, but there was a significant positive correlation between $R E T$ and $G F R \alpha 2$, and a significant negative correlation between RET and GFR $\alpha 3$; GFR 4 was expressed at very low levels in all tumors. Interestingly, there was an inverse correlation between RET and NTRKI expression, but positive correlation between RET and NTRK2. MYCN amplification status did not correlate with GFR co-receptors, but NTRK1 expression was significantly lower in tumors with $M Y C N$ amplification. These correlations were validated in additional expression datasets (2,579 cases total), and the same correlations were seen in all datasets (Fig. 6). In addition, age vs candidate $\log 2$ FPKM gene expression was compared in patients $<18$ months and $>18$ months and identified RET, GFR $\alpha 2$ and NTRK1 expressions as significant (Fig. S1). 


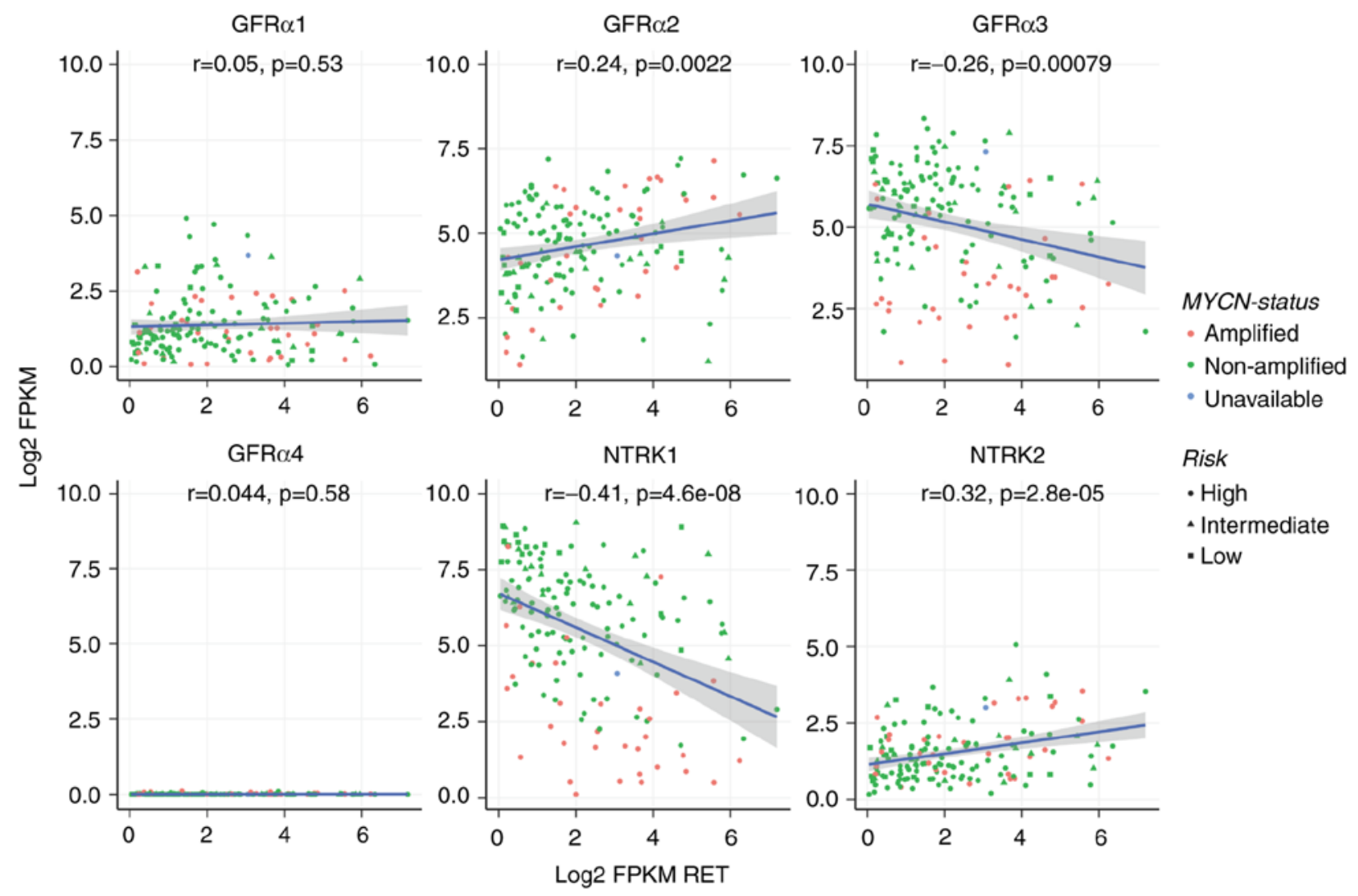

Figure 5. Correlation between RET expression with RET co-receptor and TRK genes. Scatter plot of the Log2 FPKM mRNA expression of RET vs. GFR $\alpha 1$, $-\alpha 2,-\alpha 3$, and $-\alpha 4$, as well as NTRK1 and NTRK2 for all neuroblastoma samples with RNA sequencing data. Data from 249 primary NBs from the NB TARGET Project (ocg.cancer.gov/programs/target/projects/neuroblastoma) were included in the analysis. NTRK, neurotrophic tyrosine receptor kinase.

\section{Discussion}

In the present study, it was demonstrated that RET and its co-receptors are expressed in some but not all NB cell lines. It was also demonstrated activation of RET with GDNF, NRTN and/or ARTN in the RET positive cell lines examined. RET activation by cognate ligands demonstrates intact RET function in NB cell lines that is correlated with expression of the respective GFR co-receptor.

Cell lines with the highest RET expression also had the highest GFR $\alpha 3$ expression. NLF, a RET null line, had very low GFR $\alpha 3$ expression and yet was unresponsive to ARTN. This suggests that ARTN activation of RET is primarily through GFR $\alpha 3$ and requires RET expression in NB. Baloh et al (55) first identified ARTN as a survival factor for sympathetic, sensory and mid-brain neurons. Shortly after this, Masure et al (56) described ARTN under a different name, enovin or neublastin, as inducing neurite outgrowth in SY5Y cells and rescuing them from the toxic effects of taxol. In the present study, morphologic evidence of neuronal differentiation as well as significant neurite outgrowth was noticed in SY5Y and NBLS when treated with NRTN and ARTN. Several reports have also suggested a role of GDNF, GFR $\alpha 1$ and RET in NB differentiation (9,26-33). Others have shown that RET is essential for retinoic acid induced differentiation $(9,27,32)$. Finally, Hishiki et al (57) suggested a role for NRTN and GDNF in neurological differentiation.
The intensity of phosphorylation of RET by different ligands correlated well with co-receptor mRNA and protein expression in the present study. In particular, the expression of GFR $\alpha 3$ and RET activation by ARTN were quite consistent with what was expected. Studies by others have shown that GFR $\alpha 1$ forms a physical complex with RET upon GDNF stimulation by recruiting RET into lipid rafts (58-61). Based on sequence and functional homology between GFR $\alpha 1$ and GFR $\alpha 3$ and what is known about the mechanism of interaction between GFR $\alpha 1$ and RET, it could be hypothesized that GFR $\alpha 3$ also recruits RET into lipid rafts in a similar manner. PSPN and GFR $\alpha 4$ were not examined in detail, as their mRNA and protein expression were very low/absent in the NB lines, and the literature suggests that PSPN does not play an important role in the sympathetic nervous system (55).

Previous studies have shown RET activation with TRK ligands $(37,38)$, but there are no published studies that show TRK activation with RET ligands. The present study demonstrated that treatment of NBLS, a TRK and RET positive cell line, with the RET ligand ARTN resulted in phosphorylation and activation of TRK, as well as RET. However, RET is not activated by NGF in the TRK-null SY5Y line, suggesting TrkA expression is required. Inhibition of both RET and TRK activation in the presence of a TRK inhibitor CEP-701. Was shown. Two other groups have suggested that RET and TRK crosstalk is essential for NB differentiation $(37,38)$. Further studies into RET and TRK interactions may provide a more 

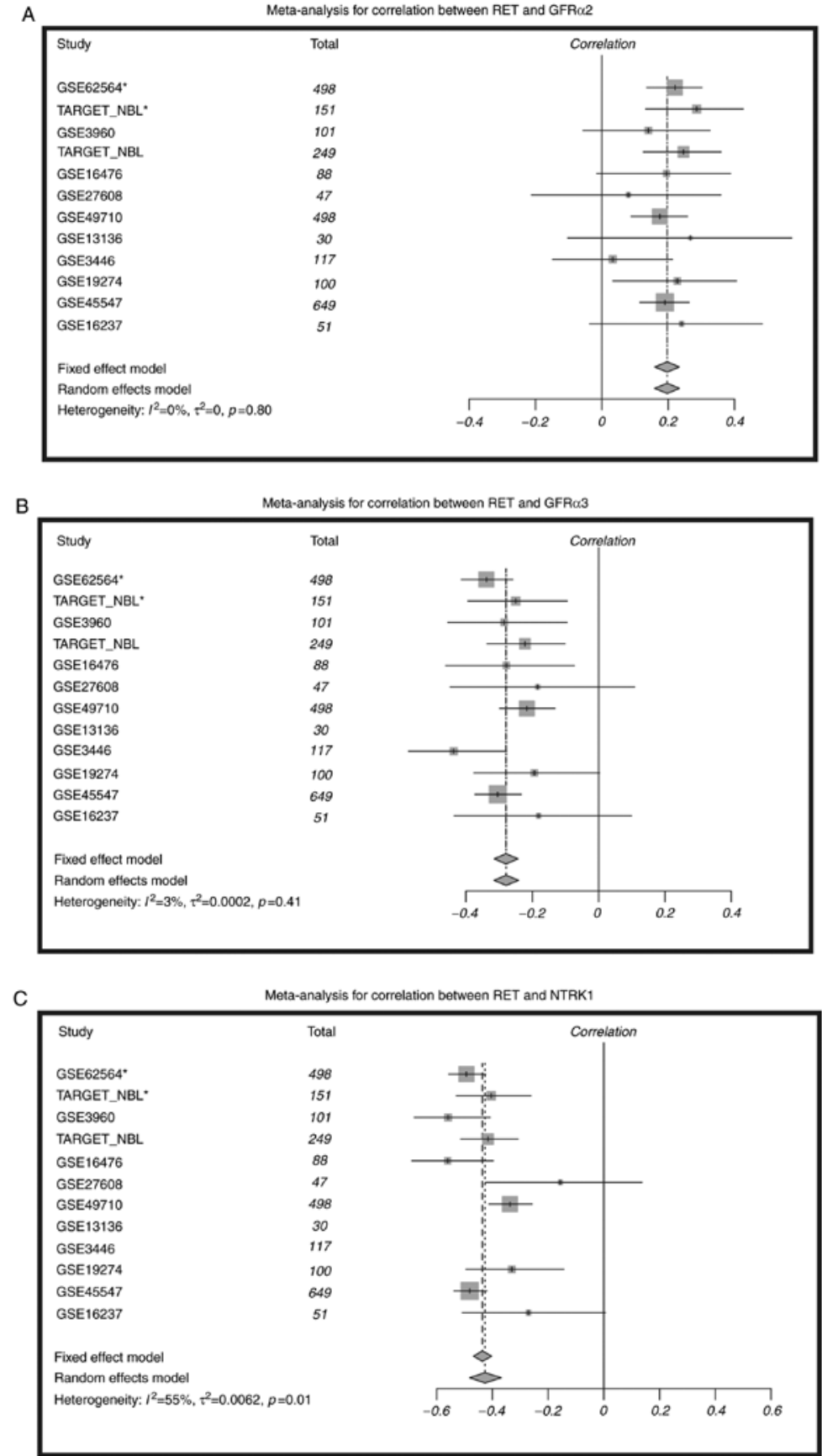

D

Meta-analysis for correlation between RET and NTRK2

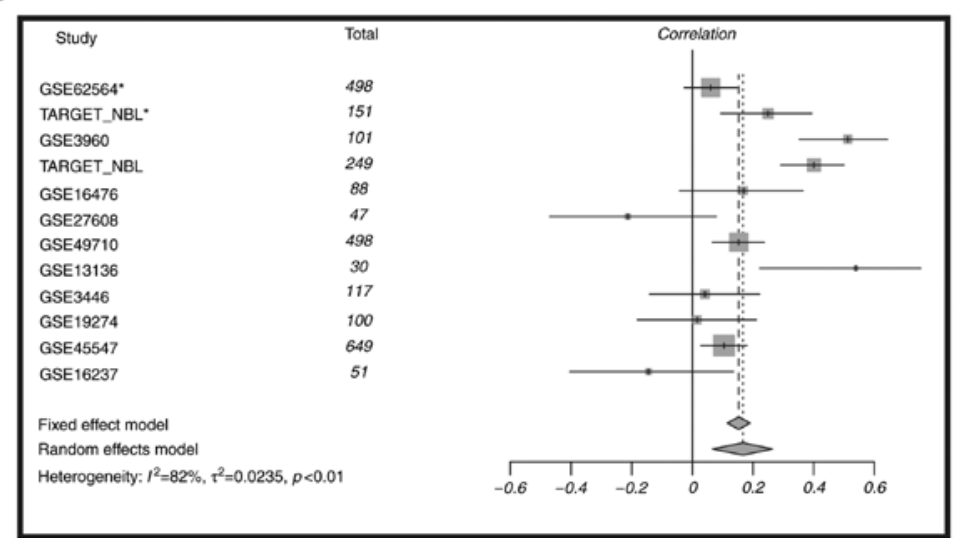

Figure 6. Correlation analysis between RET, GFR and TRK gene expression by meta-analysis. Forest plots displaying the meta-analysis of estimated Pearson's correlation of (A) RET with GFR $\alpha 2$; (B) RET with GFR $\alpha 3$; (C) RET with NTRK1 and (D) RET with NTRK2, from 12 publicly available NB microarray expression and RNA-sequencing studies. Studies with an asterisk represent RNA sequencing data. The remaining studies represent gene expression microarray data. NTRK, neurotrophic tyrosine receptor kinase. 
insight into the nature of the interaction between RET and TRK pathways.

In conclusion, the expression and function of RET and its co-receptors in NB cell lines was investigated. RET activation may play a role in differentiation of $\mathrm{NB}$ cell lines, and uninhibited RET and TRK activation are essential for survival and growth of NB cells in vitro. It was shown that TRK activation by ARTN may occur through a RET-dependent mechanism, and RET activation by TrkA in response to NGF. It has been suggested that RET and TrkB expression are both required for differentiation induced by retinoic acid, a compound known to induce differentiation in NB (37). The same study showed that RET can be activated by BDNF (37). NGF, the ligand associated with TrkA, has been shown to induce RET phosphorylation and the activation of RET and TrkA can also induce NB differentiation $(38,62)$. Understanding the importance of RET and its interactions with TRK for differentiation and survival of NB may provide new therapeutic avenues involving this complex signaling pathway.

\section{Acknowledgements}

Not applicable.

\section{Funding}

This work was supported in part from the National Institutes of Health (grant. no. R01-CA094194), Alex Lemonade Stand Foundation, and the Audrey E. Evans Chair in Molecular Oncology (GMB).

\section{Availability of data and materials}

The datasets used and/or analyzed during the present study are available from the corresponding author on reasonable request. The transfected lines are available from Kerafast (https://www. kerafast.com/contactus). Data from 249 primary NBs from the NB TARGET Project (ocg.cancer.gov/programs/target/projects/neuroblastoma) were included in the analysis.

\section{Authors' contributions}

LHT, RLG, RI, JLC, JHC, KN, PG and FN performed the experiments. KSG, PR performed the statistical analysis. LHT, VK, JLC, SPM and GMB designed the present study and wrote the manuscript. All authors read and approved the final manuscript.

\section{Ethics approval and consent to participate}

Not applicable.

\section{Patient consent for publication}

Not applicable.

\section{Competing interests}

The authors declare that they have no competing interests.

\section{References}

1. Mueller S and Matthay KK: Neuroblastoma: Biology and staging. Curr Oncol Rep 11: 431-438, 2009.

2. Brodeur GM, Hogarty MD, Bagatell R, Mosse YP and Maris JM: Neuroblastoma. In: Principles and Practice of Pediatric Oncology. Pizzo PA and Poplack DG, (eds). JB Lippincott Company, Philadelphia, PA, pp772-797, 2016.

3. Brodeur GM: Neuroblastoma: Biological insights into a clinical enigma. Nat Rev Cancer 3: 203-216, 2003.

4. Schwab M, WestermannF, Hero B and Berthold F: Neuroblastoma: Biology and molecular and chromosomal pathology. Lancet Oncol 4: 472-480, 2003.

5. Brodeur GM, Minturn JE, Ho R, Simpson AM, Iyer R, Varela CR, Light JE, Kolla V and Evans AE: Trk receptor expression and inhibition in neuroblastomas. Clin Cancer Res 15: 3244-3250, 2009.

6. Thiele CJ, Li Z and McKee AE: On Trk-the TrkB signal transduction pathway is an increasingly important target in cancer biology. Clin Cancer Res 15: 5962-5967, 2009.

7. Farinas I, Wilkinson GA, Backus C, Reichardt LF and Patapoutian A: Characterization of neurotrophin and Trk receptor functions in developing sensory ganglia: Direct NT-3 activation of TrkB neurons in vivo. Neuron 21: 325-334, 1998.

8. Borrello MG, Bongarzone I, Pierotti MA, Luksch R, Gasparini M, Collini P, Pilotti S, Rizzetti MG, Mondellini P, De Bernardi B, et al: Trk and ret proto-oncogene expression in human neuroblastoma specimens: High frequency of trk expression in non-advanced stages. Int J Cancer 54: 540-545, 1993.

9. Tahira T, Ishizaka Y, Itoh F, Nakayasu M, Sugimura T and Nagao M: Expression of the ret proto-oncogene in human neuroblastoma cell lines and its increase during neuronal differentiation induced by retinoic acid. Oncogene 6: 2333-2338, 1991.

10. Nagao M, Ishizaka Y, Nakagawara A, Kohno K, Kuwano M, Tahira T, Itoh F, Ikeda I and Sugimura T: Expression of ret proto-oncogene in human neuroblastomas. Jpn J Cancer Res 81: 309-312, 1990.

11. Arighi E, Borrello MG and Sariola H: RET tyrosine kinase signaling in development and cancer. Cytokine Growth Factor Rev 16: 441-467, 2005.

12. Enomoto H, Crawford PA, Gorodinsky A, Heuckeroth RO, Johnson EM Jr and Millbrandt J: RET signaling is essential for migration, axonal growth and axon guidance of developing sympathetic neurons. Development 128: 3963-3974, 2001.

13. Ernsberger U: The role of GDNF family ligand signalling in the differentiation of sympathetic and dorsal root ganglion. Cell Tissue Res 333: 353-337, 2008.

14. Zwick E, Bange J and Ullrich A: Receptor tyrosine kinase signalling as a target for cancer intervention strategies. Endocr Relat Cancer 8: 161-173, 2001.

15. Mulligan LM: RET revisited: Expanding the oncogenic portfolio. Nat Rev Cancer 14: 173-186, 2014.

16. Airaksinen MS, Titievsky A and Saarma M: GDNF family neurotrophic factor signaling: Four masters, one servant? Mol Cell Neurosci 13: 313-325, 1999.

17. Santoro M, Carlomagno F, Melillo RM and Fusco A: Dysfunction of the RET receptor in human cancer. Cell Mol Life Sci 61: 2954-2964, 2004.

18. Santoro M, Melillo RM, Carlomagno F, Vecchio G and Fusco A: Minireview: RET: Normal and abnormal functions. Endocrinology 145: 5448-5451, 2004.

19. Tahira T, Ishizaka Y, Itoh F, Sugimura $T$ and Nagao M: Characterization of ret proto-oncogene mRNAs encoding two isoforms of the protein product in a human neuroblastoma cell line. Oncogene 5: 97-102, 1990.

20. Tsui-Pierchala BA, Ahrens RC, Crowder RJ, Milbrandt J and Johnson EM Jr: The long and short isoforms of Ret function as independent signaling complexes. J Biol Chem 277: 34618-34625, 2002.

21. Takahashi M, Buma Y and Taniguchi M: Identification of the ret proto-oncogene products in neuroblastoma and leukemia cells. Oncogene 6: 297-301, 1991.

22. Ikeda I, Ishizaka Y, Tahira T, Suzuki T, Onda M, Sugimura T and Nagao M: Specific expression of the ret proto-oncogene in human neuroblastoma cell lines. Oncogene 5: 1291-1296, 1990.

23. Itoh F, Ishizaka $Y$, Tahira $T$, Yamamoto $M$, Miya A, Imai K, Yachi A, Takai S, Sugimura T and Nagao M: Identification and analysis of the ret proto-oncogene promoter region in neuroblastoma cell lines and medullary thyroid carcinomas from MEN2A patients. Oncogene 7: 1201-1206, 1992. 
24. Hofstra RM, Cheng NC, Hansen C, Stulp RP, Stelwagen T, Clausen N, Tommerup N, Caron H, Westerveld A, Versteeg R and Buys $\mathrm{CH}$ : No mutations found by RET mutation scanning in sporadic and hereditary neuroblastoma. Hum Genet 97: 362-364, 1996.

25. Peaston AE, Camacho ML, Norris MD, Haber M, Marsh DJ, Robinson BG, Hyland VJ and Marshall GM: Absence of MEN2A- or 2B-type RET mutations in primary neuroblastoma tumour tissue. Mol Cell Probes 12: 239-242, 1998

26. D'Alessio A, De Vita G, Cali G, Nitsch L, Fusco A, Vecchio G, Santelli G, Santoro M and de Franciscis V: Expression of the RET oncogene induces differentiation of SK-N-BE neuroblastoma cells. Cell Growth Differ 6: 1387-1394, 1995.

27. Bunone G, Borrello MG, Ricetti R, Bongarzone I, Peverali FA, de Franciscis V, Della Valle G and Pierotti MA: Induction of RET proto-oncogene expression in neuroblastoma cells precedes neuronal differentiation and is not mediated by protein synthesis. Exp Cell Res 217: 92-99, 1995.

28. Cerchia L, D'Alessio A, Amabile G, Duconge F, Pestourie C, Tavitian B, Libri D and de Franciscis V: An autocrine loop involving Ret and Glial cell-derived neurotrophic factor mediates retinoic acid-induced neuroblastoma cell differentiation. Mol Cancer Res 4: 481-488, 2006.

29. Lee RHK, Wong WL, Chan CH and Chan SY: Differential effects of glial cell line-derived neurotrophic factor and neurturin in RET/GFRalpha1-expressing cells. J Neurosci Res 83: 80-90, 2006.

30. Uchida M, Enomoto A, Fukuda T, Kurokawa K, Maeda K, Kodama Y, Asai N, Hasegawa T, Shimono Y, Jijiwa M, et al: Dok-4 regulates GDNF-dependent neurite outgrowth through downstream activation of Rap1 and mitogen-activated protein kinase. J Cell Sci 119: 3067-3077, 2006.

31. Ishida M, Ichihara M, Mii S, Jijiwa M, Asai N, Enomoto A, Kato T, Majima A, Ping J, Murakumo Y and Takahashi M: Sprouty2 regulates growth and differentiation of human neuroblastoma cells through RET tyrosine kinase. Cancer Sci 98: 815-821, 2007.

32. Oppenheimer O, Cheung NK and Gerald WL: The RET oncogene is a critical componenet of transcriptional programs associated with retinoic acid-induced differentiation in neuroblastoma. Mol Cancer Ther 6: 1300-1309, 2007.

33. Yamada S, Nomura T, Uebersax L, Matsumoto K, Fujita S Miyake M and Miyake J: Retinoic acid induces functional c-Ret tyroine kinase in human neuroblastoma. Neuroreport 18 359-363, 2007.

34. Iwamoto T, Taniguchi M, Wajjwalku W, Nakashima I and Takahashi M: Neuroblastoma in a transgenic mouse carrying a metallothionein/ret fusion gene. Br J Cancer 67: 504-507, 1993.

35. Takada N, Isogai E, Kawamoto T, Nakanishi H, Todo S and Nakagawara A: Retinoic acid-induced apoptosis of the CHP134 neuroblastoma cell line is associated with nuclear accumulation of p53 and is rescued by the GDNF/Ret signal. Med Pediatr Oncol 36: 122-126, 2001 .

36. Futami $\mathrm{H}$ and Sakai R: RET protein promotes non-adherent growth of NB-39-nu neuroblastoma cell line. Cancer Sci 100: 1034-1039, 2009.

37. Esposito CL, D'Alessio A, de Franciscis V and Cerchia L: A cross-talk between TrkB and Ret tyrosine kindases receptors mediates neuroblastoma cells differentiation. PLoS One 3 : e1643, 2008

38. Peterson S and Bogenmann E: The RET and TRKA pathways collaborate to regulate neuroblastoma differentiation. Oncogene 23: 213-225, 2004

39. Azar CG, Scavarda NJ, Nakagawara A and Brodeur GM Expression and function of the nerve growth factor receptor (TRK-A) in human neuroblastoma cell lines. Prog Clin Biol Res 385: 169-175, 1994.

40. Brodeur GM, Nakagawara A, Yamashiro DJ, Ikegaki N, Liu XG, Azar CG, Lee CP and Evans AE: Expression of TrkA, TrkB and TrkC in human neuroblastomas. J Neurooncol 31: 49-55, 1997

41. Croucher JL, Iyer R, Li N, Molteni V, Loren J, Gordon WP, Tuntland T, Liu B and Brodeur GM: TrkB inhibition by GNF-4256 slows growth and enhances chemotherapeutic efficacy in neuroblastoma xenografts. Cancer Chemother Pharmacol 75: 131-141, 2015.

42. Eggert A, Ikegaki N, Liu X, Chou TT, Lee VM, Trojanowski JQ and Brodeur GM: Molecular dissection of TrkA signal transduction pathways mediating differentiation in human neuroblastoma cells. Oncogene 19: 2043-2051, 2000.
43. Eggert A, Ikegaki N, Liu XG and Brodeur GM: Prognostic and biological role of neurotrophin-receptor TrkA and TrkB in neuroblastoma. Klin Padiatr 212: 200-205, 2000.

44. Evans AE, Kisselbach KD, Liu X, Eggert A, Ikegaki N, Camoratto AM, Dionne C and Brodeur GM: Effect of CEP-751 (KT-6587) on neuroblastoma xenografts expressing TrkB. Med Pediatr Oncol 36: 181-184, 2001.

45. Ho R, Eggert A, Hishiki T, Minturn JE, Ikegaki N, Foster P, Camoratto AM, Evans AE and Brodeur GM: Resistance to chemotherapy mediated by TrkB in neuroblastomas. Cancer Res 62: 6462-6466, 2002

46. Ho R, Minturn JE, Simpson AM, Iyer R, Light JE, Evans AE and Brodeur GM: The effect of P75 on Trk receptors in neuroblastomas. Cancer Lett 305: 76-85, 2011.

47. Iyer R, Evans AE, Qi X, Ho R, Minturn JE, Zhao H, Balamuth N, Maris JM and Brodeur GM: Lestaurtinib enhances the antitumor efficacy of chemotherapy in murine xenograft models of neuroblastoma. Clin Cancer Res 16: 1478-1485, 2010.

48. Iyer R, Varela CR, Minturn JE, Ho R, Simpson AM, Light JE, Evans AE, Zhao H, Thress K, Brown JL and Brodeur GM: AZ64 inhibits TrkB and enhances the efficacy of chemotherapy and local radiation in neuroblastoma xenografts. Cancer Chemother Pharmacol 70: 477-486, 2012.

49. Iyer R, Wehrmann L, Golden RL, Naraparaju K, Croucher JL, MacFarland SP, Guan P, Kolla V, Wei G, Cam N, et al: Entrectinib is a potent inhibitor of Trk-driven neuroblastomas in a xenograft mouse model. Cancer Lett 372: 179-186, 2016.

50. Nakagawara A, Arima-Nakagawara M, Scavarda NJ, Azar CG, Cantor AB and Brodeur GM: Association between high levels of expression of the TRK gene and favorable outcome in human neuroblastoma. N Engl J Med 328: 847-854, 1993.

51. Nakagawara A, Azar CG, Scarvarda NJ and Brodeur GM: Expression and function of TRK-B and BDNF in human neuroblastomas. Mol Cell Biol 14: 759-767, 1994.

52. Redden RA, Iyer R, Brodeur GM and Doolin EJ: Rotary bioreactor culture can discern specific behavior phenotypes in Trk-null and Trk-expressing neuroblastoma cell lines. In Vitro Cell Dev Biol Anim 50: 188-193, 2014.

53. Wickham H: Ggplot2: Elegant Graphics for Data Analysis. Springer-Verlag, New York, NY, 2009.

54. Schwarzer G, Carpenter JR and Rucker G: Meta-Analysis with R (Use-R!). Springer International Switzerland, Basel, 2015.

55. Baloh RH, Tansey MG, Lampe PA, Fahrner TJ, Enomoto H, Simburger KS, Leitner ML, Araki T, Johnson EM Jr and Milbrandt J: Artemin, a novel member of the GDNF ligand family, supports peripheral and central neurons and signals through the GFRalpha3-RET receptor complex. Neuron 21: 1291-1302, 1998

56. Masure S, Geerts H, Cik M, Hoefnagel E, Van Den Kieboom G, Tuytelaars A, Harris S, Lesage AS, Leysen JE, Van Der Helm L, et al: Enovin, a member of the glial cell-line-derived neurotrophic factor (GDNF) family with growth promoting activity on neuronal cells. Existence and tissue-specific expression of different splice variants. Eur J Biochem 266: 892-902, 1999.

57. Hishiki T, Nimura Y, Isogai E, Kondo K, Ichimiya S, Nakamura Y, Ozaki T, Sakiyama S, Hirose M, Seki N, et al: Glial cell line-derived neurotrophic factor/neurturin-induced differentiation and its enhancement by retinoic acid in primary human neuroblastomas expressing c-Ret, GFRalpha-1 and GFRalpha-2. Cancer Res 58: 2158-2165, 1998

58. Tansey MG, Baloh RH, Milbrandt $\mathbf{J}$ and Johnson EM Jr: GFRalpha-mediated localization of RET to lipid rafts is required for effective downstream signaling, differentiation, and neuronal survival. Neuron 25: 611-623, 2000.

59. Pierchala BA, Milbrandt J and Johnson EM Jr: Glial cell line-derived neurotrophic factor-dependent recruitment of Ret into lipid rafts enhances signaling by partitioning Ret from proteasome-dependent degradation. J Neurosci 26: 2777-2787, 2006

60. Richardson DS, Lai AZ and Mulligan LM: RET ligand-induced internalization and its consequences for downstream signaling. Oncogene 25: 3206-3211, 2006.

61. Lundgren T, Luebke M, Stenqvist A and Ernfors P: Differential membrane compartmentalization of Ret by PTB-adaptor engagement. FEBS J 275: 2055-2066, 2008.

62. Tsui-Pierchala BA, Millbrandt $\mathbf{J}$ and Johnson EM Jr: NGF utilizes c-Ret via a novel GFL-independent, inter-RTK signaling mechanism to maintain the trophic status of mature sympathetic neurons. Neuron 33: 261-273, 2002. 